\title{
Protective Effect Of Vasicine Against Myocardial Infarction In Rats Via Modulation Of Oxidative Stress, Inflammation, And The PI3K/Akt Pathway
}

This article was published in the following Dove Press journal:

Drug Design, Development and Therapy

\author{
Tiechao Jiang ${ }^{1,2}$ \\ Lirong Zhang ${ }^{3}$ \\ Mei Ding ${ }^{1,2}$ \\ Min $\mathrm{Li}^{4}$
}

'Department of Cardiovascular Medicine, China-Japan Union Hospital of Jilin University, Changchun 130033, People's Republic of China; ${ }^{2}$ jilin Provincial Precision Medicine Key Laboratory for Cardiovascular Genetic Diagnosis, Changchun 130033, People's Republic of China; ${ }^{3}$ Department of Pathology, ChinaJapan Union Hospital of Jilin University, Changchun 130033, People's Republic of China; ${ }^{4}$ Department of Clinical Laboratory, China-Japan Union Hospital of Jilin University, Changchun I30033, People's Republic of China
Correspondence: Mei Ding

Department of Cardiovascular Medicine, China-Japan Union Hospital of Jilin

University, 126 Xiantai St, Erdao,

Changchun 130033, People's Republic of China

Tel +86-43I-84995258

Email LeahRamosjsr@yahoo.com

Min Li

Department of Clinical Laboratory,

China-Japan Union Hospital of Jilin

University, 126 Xiantai St, Erdao,

Changchun 130033, People's Republic of

China

Tel +86-43I-84995646

Email m68555I2helin8@I63.com
Background: Myocardial infarction is the leading cause of damage to the heart and is classified as a major cause of death related to cardiovascular disease. In the present study, we intended to investigate the protective effect of vasicine (VAS) against myocardial infarction in rats, and its mechanism.

Methods: Myocardial infarction was induced by isoproterenol (ISO, $100 \mathrm{mg} / \mathrm{kg}$ ) at an interval of $24 \mathrm{~h}$ for 2 days. Different doses of VAS $(2.5,5$, and $10 \mathrm{mg} / \mathrm{kg}$ body weight) were administered to the rats. The effect of VAS on oxidative stress markers such as, myocardial necrosis, myocardial ability and infarct volume, inflammatory cytokines, membrane-bound myocardial enzymes, and histopathological changes was investigated. Western blot analysis was also conducted to analyze the effect of VAS on autophagy (PI3K/Akt) and apoptosis (Bcl-2, Bax, and caspase-3). The number of apoptotic cells in the different groups was also identified using TUNEL.

Results: Results suggested that VAS causes reduction in myocardial necrosis by reduction of elevated LDH, CK-MB, and TnT levels. It also causes augmentation of left ventricular systolic pressure (LVSP) and myocardial contractility as determined in terms of $+\mathrm{dp} / \mathrm{dt}_{\text {max }}$ and $-\mathrm{dp} / \mathrm{dt}_{\max }$. Furthermore, VAS causes reduction of TNF- $\alpha$ and IL-6 levels. VAS also improved cardiac function via enhancing posterior wall thickness of the LV with concurrent increase in the mass of LV. In the present study, VAS caused activation of phosphorylated PI3K (p-PI3K) and phosphorylated Akt (p-Akt) in a dose-dependent manner. Furthermore, VAS suppressed apoptosis when tested on animals suffering from ISO-induced MI, by decreasing the expression of cleaved Caspase- 3 and Bax while increasing the expression of Bcl-2.

Conclusion: In conclusion, vasicine has a protective effect against MI in vivo, through inhibiting oxidative stress, inflammation and excessive autophagy, to suppress apoptosis via activation of the PI3K/Akt/mTOR signaling pathway.

Keywords: myocardial infarction, vasicine, TNF- $\alpha$, IL-6, PI3K, Akt, Bcl-2

\section{Introduction}

Myocardial infarction is the leading cause of damage to the heart and classified as a major cause of death related to cardiovascular diseases. This leads to significant damage to myocardial tissues due to less oxygen supply (ischemia) resulting from severe impairment of coronary blood supply. The deficiency of oxygen causes a cascade of unexpected biochemical and metabolic alterations within the myocardial tissue. ${ }^{1,2}$ Therefore, therapeutic intervention to treat myocardial ischemia is highly concentrated toward restoration of blood supply to maintain normal oxygen level 
using thrombolytics or primary percutaneous coronary intervention (PPCI). ${ }^{3-6}$ The subsequent generation of oxidative stress, inflammation, calcium overload, cellular autophagy, and apoptosis further worsen the situation. ${ }^{7}$ The clinical approaches for cardio-protection face numerous hurdles. It has been widely seen that, the translation of novel cardioprotective therapies into the clinical setting for patient benefit has been extremely difficult. In the past decades, a huge number of therapies with proven efficacy for preventing myocardial reperfusion injury and reducing MI size in experimental animal studies (eg, antioxidants, magnesium, calcium-channel blockers, anti-inflammatory agents, erythropoietin, atorvastatin, glucose-insulin potassium therapy, adenosine) have produced inadequate response when examined in the clinical situation as a supporting therapy to reperfusion. ${ }^{8-12}$ Therefore, many scientists around the world are still working on the discovery of effective cardioprotective agents.

Compounds originating from plant sources have been receiving considerable attention in the last few decades for the treatment of various life-threatening diseases or disorders. According to various studies, plant based medicines constitute a major portion of drugs used in clinical practice, and the market for herbal medicine is expected to reach $\$ 111$ billion by the end of $2023 .^{13-16}$ Vasicine (VAS), an alkaloid belonging to the chemical class of pyrrolo 2,1-b quinazoline is isolated from Adhatoda vasica Nees (Acanthaceae). ${ }^{17}$ It possesses diverse biological properties such as, acetylcholine esterase inhibition, ${ }^{18,19}$ anti-inflammatory and anti-microbial, ${ }^{20}$ anti-oxidant $^{21,22}$ and abortifacient effects. ${ }^{23,24}$ Various studies reported the protective effect of antioxidant compounds against $\mathrm{MI}^{25-27}$ In light of the strong antioxidant nature of VAS, it is hypothesized that, VAS might act as cardioprotective agent against myocardial infarction and its after effects. Therefore, in the present study, we intended to investigate the protective effect of VAS against myocardial infarction in rats, and its mechanism.

\section{Materials And Methods}

\section{Chemicals}

Vasicine (VAS) and the other chemicals used in the present study were procured from Sigma-Aldrich (USA).

\section{Animals}

For the study, adult male Sprague-Dawley (240-270 gm) rats were obtained from the institutional animal house and were caged in individual manner in polypropylene cages under controlled temperature and humidity with alternate dark and light cycle and food and water ad libitum.

\section{Induction Of Experimental Myocardial Infarction}

Isoproterenol (ISO) was dissolved in normal saline (vehicle) and injected subcutaneously into rats $(100 \mathrm{mg} / \mathrm{kg})$ at an interval of $24 \mathrm{~h}$ for 2 days to induce experimental MI, i.e., on 6th and 7th day with an interval of $24 \mathrm{~h}$ to induce MI. Animals were sacrificed $48 \mathrm{hrs}$ after the first injection of isoproterenol for examination.

\section{Experimental Design}

The animals were grouped as eight rats $(n=8)$ in each group. Group 1: rats were administered normal saline $(2 \mathrm{~mL} / \mathrm{kg}, \mathrm{p}$. o. per day) for 7 days. Group 2: rats were administered normal saline (2 $\mathrm{mL} / \mathrm{kg}$, p.o. per day) for 7 days and challenged with ISO $(100 \mathrm{mg} / \mathrm{kg}$, s.c.) on the 6 th and 7 th day. Group 3: rats were pre-treated with $2.5 \mathrm{mg} / \mathrm{kg}$ (VAS) for 7 days and challenged with ISO $(100 \mathrm{mg} / \mathrm{kg}$, s.c.) on the 6th and 7th day. Group 4: rats were pre-treated with $5 \mathrm{mg} /$ $\mathrm{kg}$ (VAS) for 7 days and challenged with ISO (100 mg/kg, s.c.) on the 6th and 7th day. Group 5: rats were pre-treated with $10 \mathrm{mg} / \mathrm{kg}$ (VAS) for 7 days and challenged with ISO $(100 \mathrm{mg} / \mathrm{kg}$, s.c.) on the 6th and 7 th day.

After $24 \mathrm{~h}$ of the last dose of VAS, animals were weighed and blood was withdrawn from the tail vein using urethane ( $1 \mathrm{~g} / \mathrm{kg}$, intraperitoneally). Serum was then prepared from the collected blood samples and immediately stored at $-20^{\circ} \mathrm{C}$ for various biochemical estimations. Animals were then euthanized under mild anesthesia and hearts were removed, washed with normal saline, soaked, and weighed. A small piece of heart sample was preserved in formalin solution $(10 \%)$ for histopathology. Remaining heart tissues were kept at $-20^{\circ} \mathrm{C}$ for biochemical estimations.

\section{Estimation Of Cardiac Injury Markers LDH And CK In Serum}

The levels of lactate dehydrogenase (LDH) and creatine kinase $(\mathrm{CK})$ were estimated with kits from Nanjing Jiancheng Bioengineering Institute (Nanjing, China) in serum. The procedure was performed according to the instructions provided by the supplier. The results are presented as IU/L.

\section{Evaluation Of Hemodynamic Parameters}

Twenty-four hours after the final administration of VAS, rats were anesthetized with urethane $(1 \mathrm{~g} / \mathrm{kg}$, i.p.). The right common carotid artery was cannulated with a $2-\mathrm{F}$ polyethylene catheter into the left ventricle. The pressure of the blood 
was recorded and amplified by a pressure transducer via insertion of the Millar vessel into the left ventricular capacity. The left ventricular systolic pressure (LVSP) and $\pm \mathrm{dp} / \mathrm{dt}_{\max }$ were recorded by BL-420E monitor system. ${ }^{28}$

\section{Assessment Of Infarct Size}

After measurement of cardiac function, rats were sacrificed, the aorta was cannulated and 1\% 2,3,5-triphenyltetrazolium chloride (1.5\%; Sigma-Aldrich Co.) was perfused into the aorta and coronary arteries after the reperfusion. Infarct size of the heart was incubated at $37^{\circ} \mathrm{C}$ for $30 \mathrm{~min}$ in the dark. Then the ligature around the left main coronary artery was retightened and the area of the myocardium was stained with $2 \mathrm{~mL}$ of $2 \%$ Evans blue dye through aorta by the patent coronary arteries. The infarct size area was measured by blue staining and the area at risk was determined by negative staining. The heart area with brick red was regarded as normal myocardium, but the area without color was regarded as the ischemic heart muscles. ${ }^{29}$

\section{Assessment Of Serum Levels Of Tn-T, TNF- $\alpha$, And IL- 6}

The blood samples were collected and serum was isolated. The serum levels of Tn-T, TNF- $\alpha$, and IL- 6 were measured using ELISA commercial kits, according to the manufacturer's instructions (Beyotime Institute of Biotechnology, Nanjing, China). ${ }^{29}$

\section{Determination Of The Level Of MDA, SOD, GPx, And MPO Activities}

The level of MDA, SOD, GPx, and MPO activities in myocardial tissues were quantified using commercial kits, according to the manufacturer's instructions (Beyotime Institute of Biotechnology, Nanjing, China). ${ }^{30}$

\section{Histopathological Examination Of Heart (HE Staining)}

Heart tissue was soaked in $4 \%$ poly formaldehyde solution and fixed for $24 \mathrm{hr}$, processed and paraffin embedded as per the standard protocol. Sections of $5 \mu \mathrm{m}$ thickness were cut, deparaffinized, dehydrated, and stained with hematoxylin and eosin $(\mathrm{H} \& \mathrm{E})$ for the estimation of pathological changes of heart by an optical microscope and photographed using a microscope digital camera. The pathological changes in heart tissues were observed under a light microscope and images were captured at magnification, $\times 40$.

\section{Cell Apoptosis Rate In Myocardium Tissue By TUNEL} The cell apoptosis rate in myocardium tissue was detected by ApopTag ${ }^{\circledR}$ fluorescein in situ cell death detection kit after being fixed in $4 \%$ phosphate-buffered paraformaldehyde overnight. The nucleus was colored blue by DAPI, and the apoptotic cells were colored green. The cell color was observed under spectromicroscope, and the apoptosis rate was the percentage of positive cells in all DAPI-colored cells. Average value was taken from five views. ${ }^{31}$

\section{Western Blot Analysis}

Nuclear protein and cytoplasmic protein were extracted from heart tissue using nuclear and cytoplasm extraction kits, respectively, according to the manufacturer's instructions. The protein concentration was determined by bicinchoninic acid methods. Forty micrograms of protein samples were loaded and separated by SDS-PAGE and transferred to polyvinylidene fluoride membranes. The membranes were blocked with skim milk (5\%) at room temperature for $2 \mathrm{hrs}$. Then the membranes were incubated with primary antibodies, (1:1000) at $4^{\circ} \mathrm{C}$ overnight. Following primary antibody incubations, the secondary antibodies (anti-rabbit or anti-mouse IgG [1:2000]) were incubated for $1 \mathrm{hr}$ at room temperature. The bands were visualized using enhanced chemiluminescence detection reagents and gel imaging system. The gray value ratio of the target band and the $\beta$-actin band was calculated by ImageJ to represent the relative expression of the target protein. ${ }^{31}$

\section{Statistical Analysis}

All results are presented as the mean \pm SEM. The statistical results were evaluated using one-way ANOVA followed by post-hoc analysis using Tukey's multiple comparison test using GraphPad Prism software. $\mathrm{P}<0.05$ was considered a statistically significant difference.

\section{Results \\ Effect Of VAS On The ISO-Induced Myocardial Necrosis}

The effect of VAS was investigated on lactate dehydrogenase (LDH) and creatine kinase - MB (CK-MB) in the serum of myocardial tissues after injury induced by isoproterenol (ISO). As shown in Figure 1, in the ISO-treated group, the level of LDH and CK-MB was found to be enhanced $(\mathrm{P}<0.05)$, while in VAS treated group, the level of these biomarkers was found to be reduced $(\mathrm{P}<0.01)$. The maximum activity was achieved in the case of $10 \mathrm{mg} /$ $\mathrm{kg}$ treatment group.

\section{Effect Of VAS On The Myocardial Ability And Infarct Size}

The next part of the study was conducted to determine the effect of VAS on the ability to improve myocardial function. 
A

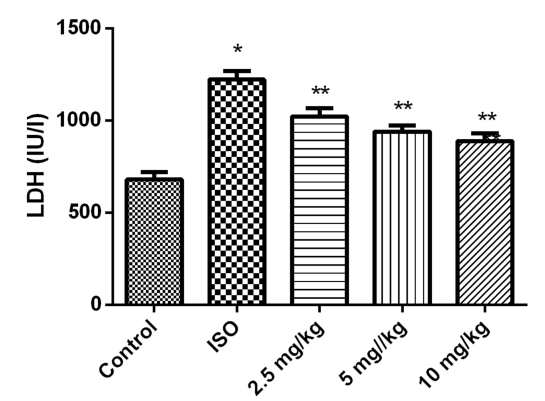

B

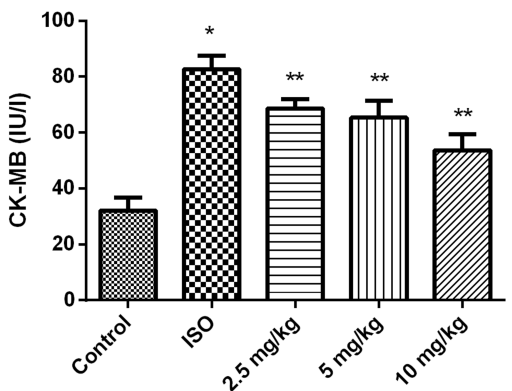

C

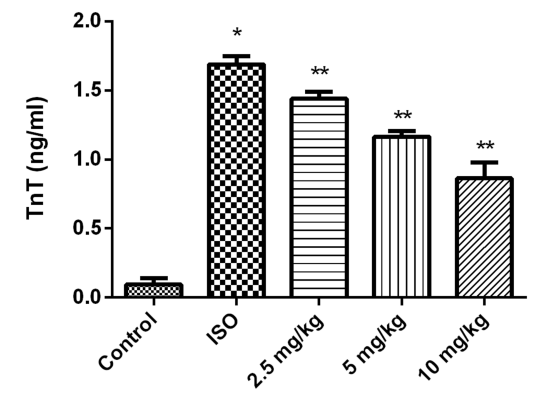

Figure I Effect of VAS on the serum (A) LDH, (B) CK-MB, and (C) TnT levels. Values represent the mean \pm SEM and are representative of three independent experiments. $* \mathrm{P}<0.05$ vs control; ${ }^{*} \mathrm{P}<0.0$ I vs ISO.

A

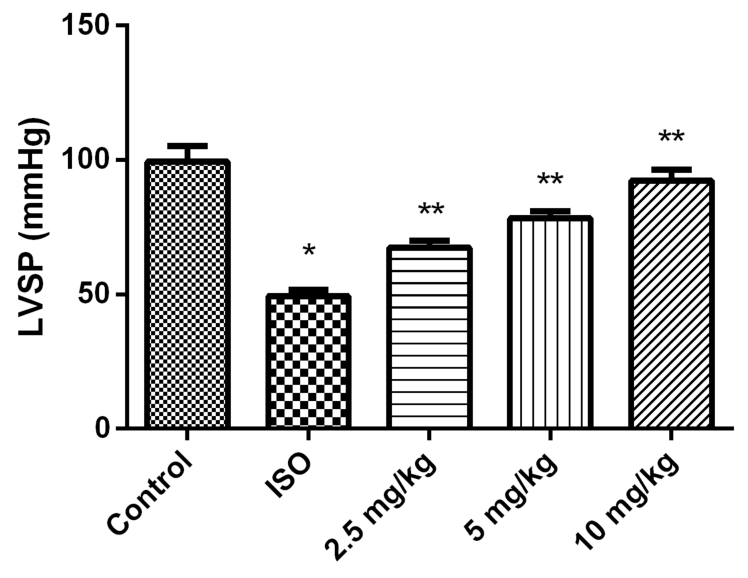

C

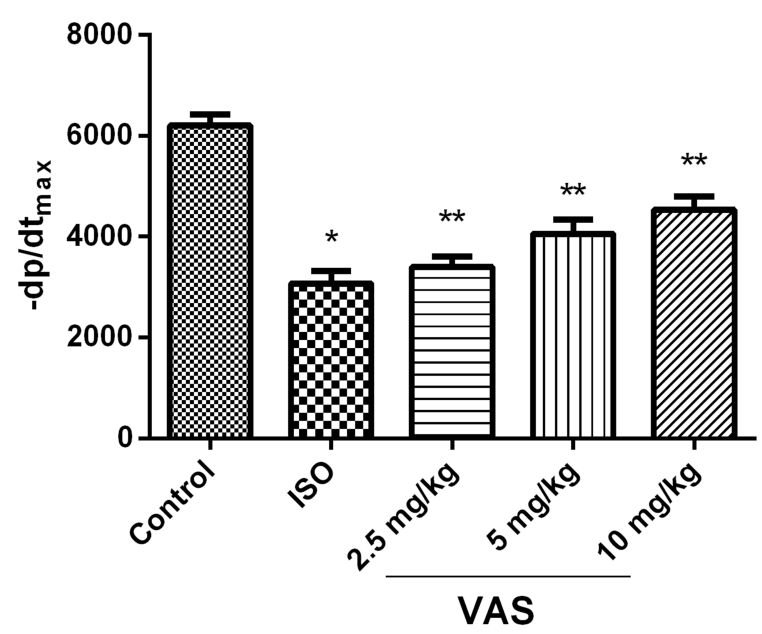

B
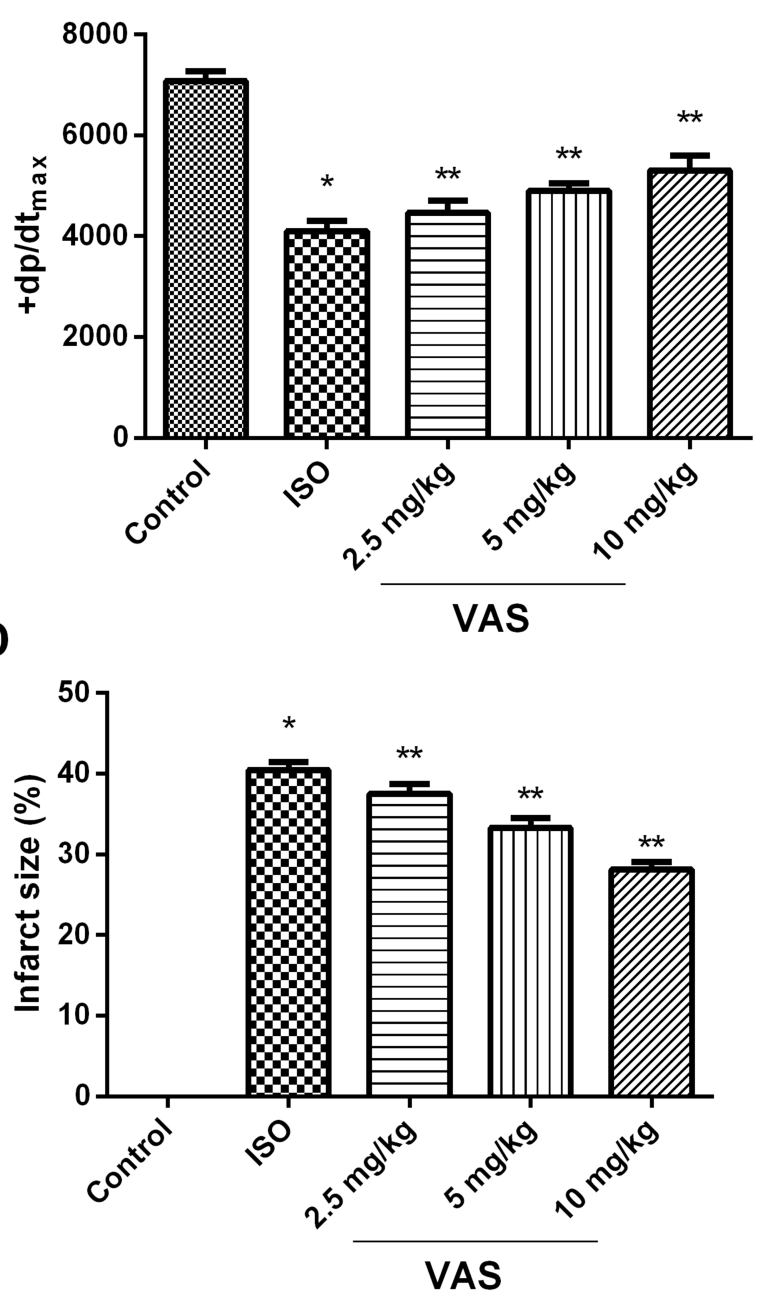

Figure 2 Effect of VAS on cardiac ability. (A) LVSP, (B) $+\mathrm{dp}^{\mathrm{d}} / \mathrm{dt}_{\max }(\mathbf{C})-\mathrm{dp}_{\mathrm{m}} / \mathrm{dt}_{\max }$, (D) infarct size. Values represent the mean $\pm \mathrm{SEM}$ and are representative of three independent experiments. $* \mathrm{P}<0.05$ vs control; $* * \mathrm{P}<0.01$ vs ISO.

As shown in Figure 2A-C, it was found that VAS causes significant improvement in left ventricular systolic pressure (LVSP) and myocardial contractility as determined in terms of $+\mathrm{d} p / \mathrm{dt}_{\max }$ and $-\mathrm{d} p / \mathrm{d} t_{\max }$ after ISO insult at $24 \mathrm{~h}$ at $10 \mathrm{mg} / \mathrm{kg}$. It has also been suggested that VAS causes considerable lowering of infarct size as compared to ISO-group (Figure 2D). 
Effect Of VAS On Tn-T, TNF- $\alpha$, And IL- 6

\section{Expression In Serum}

As shown in Figure 3, it was found that $10 \mathrm{mg} / \mathrm{kg}$ VAS treated group had a significant reduction in the level of cardiac specific troponin (Tn-T), tumour necrosis factor- $\alpha$ (TNF- $\alpha$ ), and interleukin-6 (IL-6) as compared to ISO-group ( $\mathrm{P}<0.01)$.

\section{Effect Of VAS On The Oxidative Stress Markers}

The effect of VAS was investigated on oxidative stress markers, such as, malondialdehyde (MDA), myeloperoxidase (MPO), glutathione peroxidase-1 (GPx), and superoxide dismutase (SOD), Figure 4. In VAS-treated group, the level of GPx and SOD was found to be enhanced, while the level of MPO and MDA declined significantly ( $<<0.01)$, as compared to ISO group, in a dose-dependent manner.

\section{Effect Of VAS On Cardiac Function}

As shown in Table 1, it was found that VAS causes considerable advancement in the posterior wall thickness of the LV with concurrent increase in the mass of LV. The end-systolic volume (ESV) was found to be elevated in VAS treated group, with prominent action in $10 \mathrm{mg} / \mathrm{kg}$ treated group.

\section{Effect Of VAS On The Histopathology Of Cardiac Tissues}

The histopathology of myocardial tissues was analyzed to determine the effect of VAS on microstructure level. It was

\section{A}

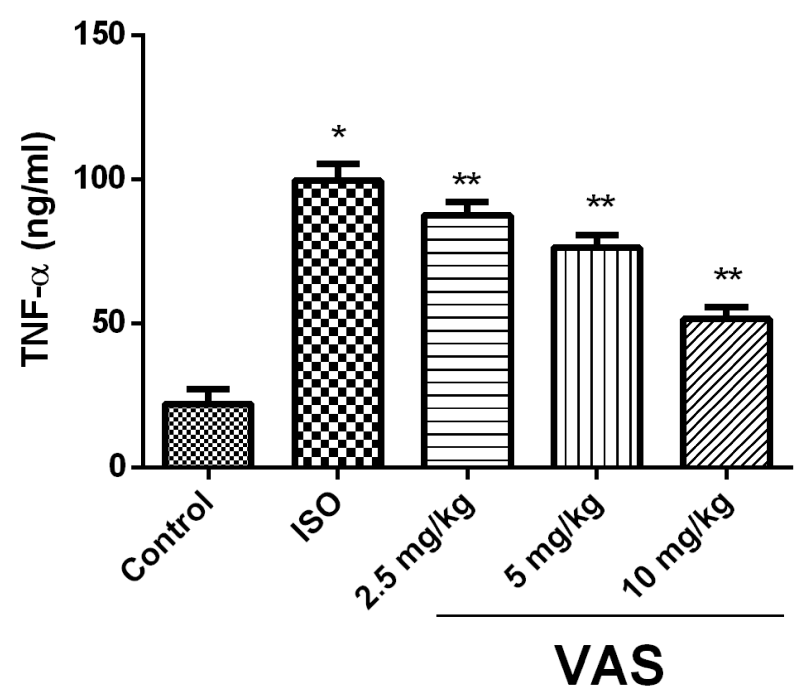

found that, the control group showed intact and homogenous histoarchitecture with no evidence of necrosis and inflammation. The ISO group showed marked confluent necrosis of muscle fibers with edema. In VAS treated group, the decreased myonecrosis, edema with mild focal inflammation, and myocyte proliferation confirm the protective effect of VAS against the ISO induced changes as shown in Figure 5.

\section{Effect Of VAS On MAPKs Protein Expressions}

The effect of VAS was investigated on the p38/JNK expressions which have been found to be highly upregulated in apoptotic and inflammatory reactions in the myocardium during infarction. As shown in Figure $6 \mathrm{~A}-\mathrm{C}$, the upregulated level of $\mathrm{p} 38 / \mathrm{JNK}$ was found to be reduced after administration of VAS as compared to ISO group.

\section{Effect Of VAS On PI3K/Akt Signaling Pathway}

The PI3K/Akt signaling pathway is significantly involved in autophagy. Thus, the effect of VAS was investigated on the expression of phosphorylated PI3K (p-PI3K) and Akt (p-Akt) in different groups by Western blot. Results suggested that, the low expression of $\mathrm{p}$-Akt and $\mathrm{p}$-PI3K induced by ISO was up-regulated by VAS treatment in a dose-dependent manner (Figure 7A-D).
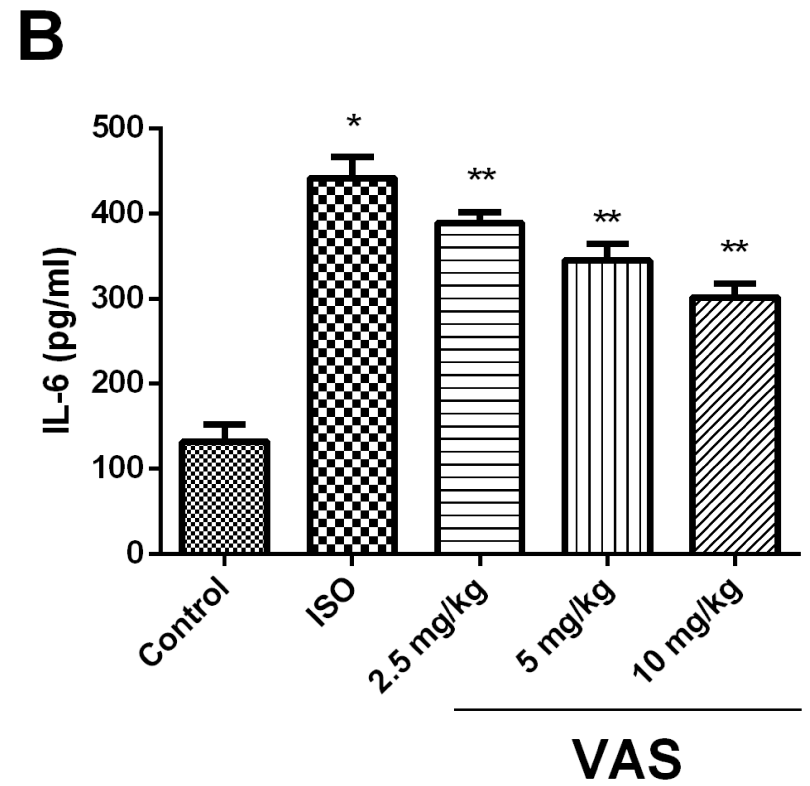

Figure 3 Effect of VAS on (A) TNF- $\alpha$ and (B) IL-6. Values represent the mean \pm SEM and are representative of three independent experiments. *P $<0.05$ vs control; **P $<0.0$ I vs ISO. 
A

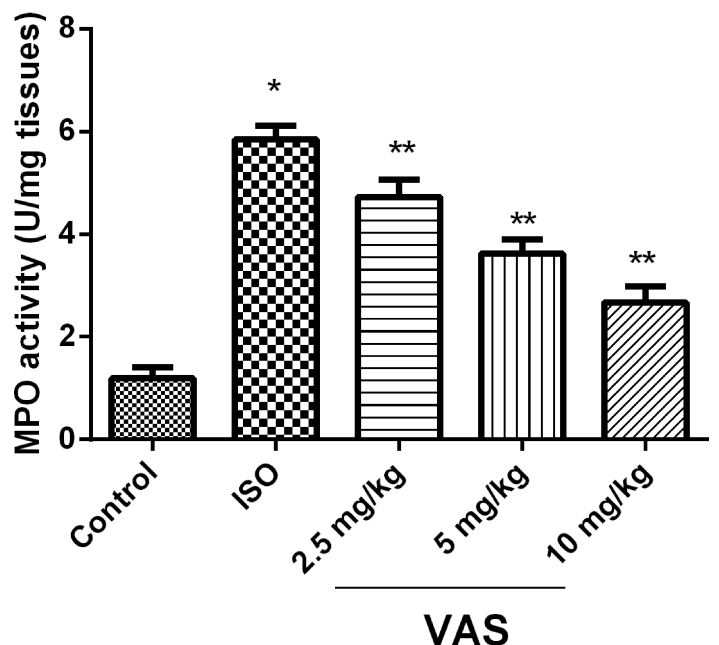

C

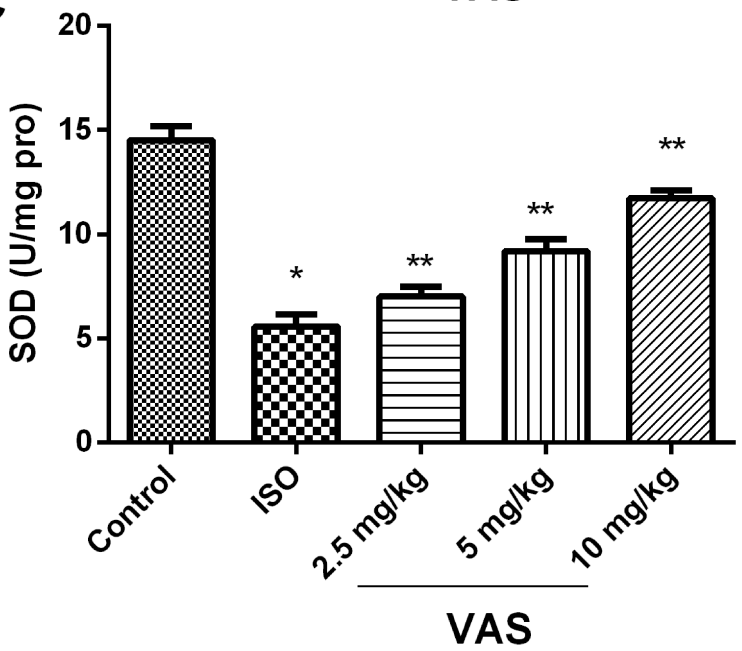

B
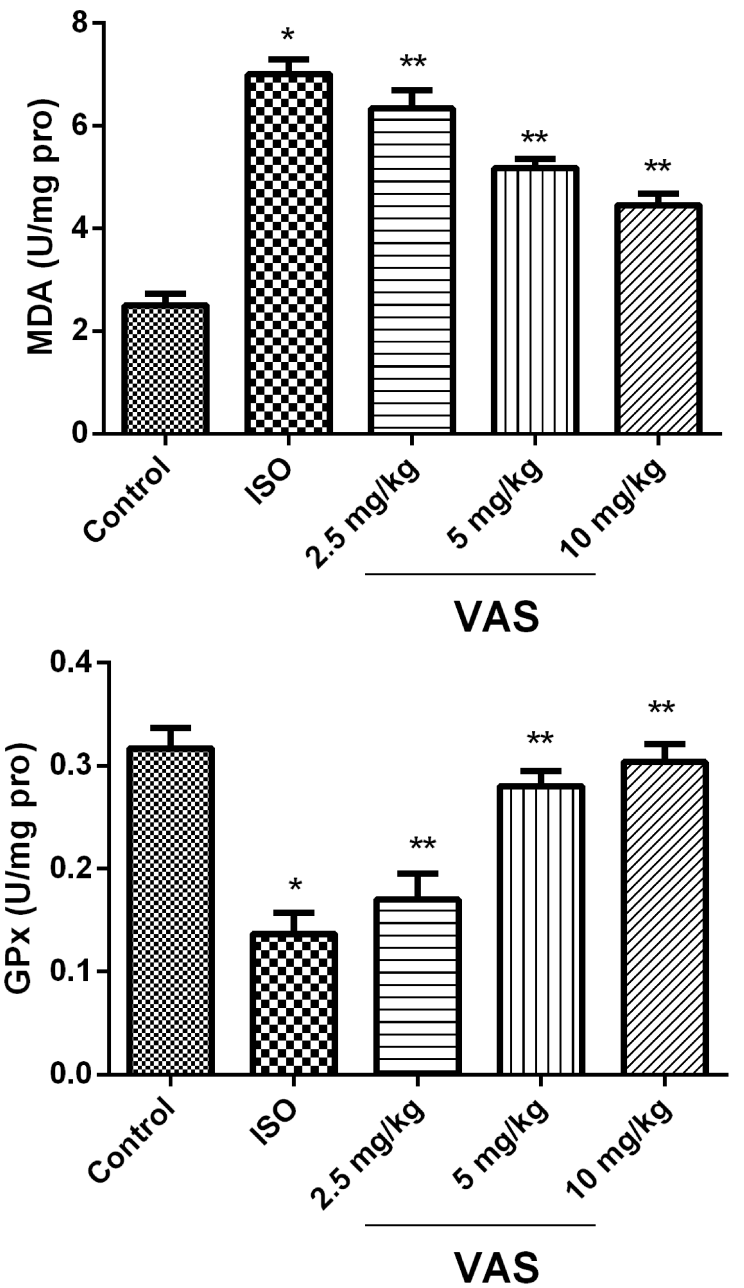

Figure 4 Effect of VAS on oxidative stress. (A) MPO, (B) MDA, (C) SOD, and (D) GPx. Values represent the mean \pm SEM and are representative of three independent experiments. $* \mathrm{P}<0.05$ vs control; $* * \mathrm{P}<0.0$ I vs ISO.

\section{Effect Of VAS On Apoptosis}

The effect of VAS on apoptosis was further evaluated by analyzing its effect against apoptotic biomarkers by

Table I The Effect Of VAS On Cardiac Function In Rats (Echo Readings)

\begin{tabular}{|l|l|l|}
\hline Parameters & Pre & Post \\
\hline PWT $(\mathrm{mm})$ & $1.270 \pm 0.02$ & $1.43 \pm 0.01$ \\
LVM $(\mathrm{g})$ & $1.13 \pm 0.03$ & $1.32 \pm 0.02$ \\
AD $(\mathrm{mm})$ & $3.34 \pm 0.12$ & $3.72 \pm 0.16$ \\
ESV $(\mu \mathrm{L})$ & $149 \pm 6$ & $199 \pm 12$ \\
EDV $(\mu \mathrm{L})$ & $332 \pm 14$ & $392 \pm 18$ \\
EF $(\%)$ & $56.7 \pm 2.1$ & $51.3 \pm 2.7$ \\
Cl $(\mu \mathrm{L} /[\mathrm{min} g])$ & $192 \pm 5$ & $171 \pm 3$ \\
\hline
\end{tabular}

Western blot. The expression of Caspase- 3 and Bax was found to be up-regulated, together with reduced level of Bcl-2 in ISO-group, whereas the levels of these proteins were restored to normal by VAS in a dose-dependent manner, for instance, VAS caused down-regulation of caspase- 3 and Bax, while, Bcl-2 was found to be enhanced (Figure 8A-D).

\section{Effect Of VAS On Apoptosis By TUNEL}

\section{Assay}

TUNEL staining showed apoptotic rate in ISO group was highly elevated compared to control. On the contrary, the apoptosis rate was markedly reduced in the VAS treated group as compared to ISO group, as shown in Figure 9. 


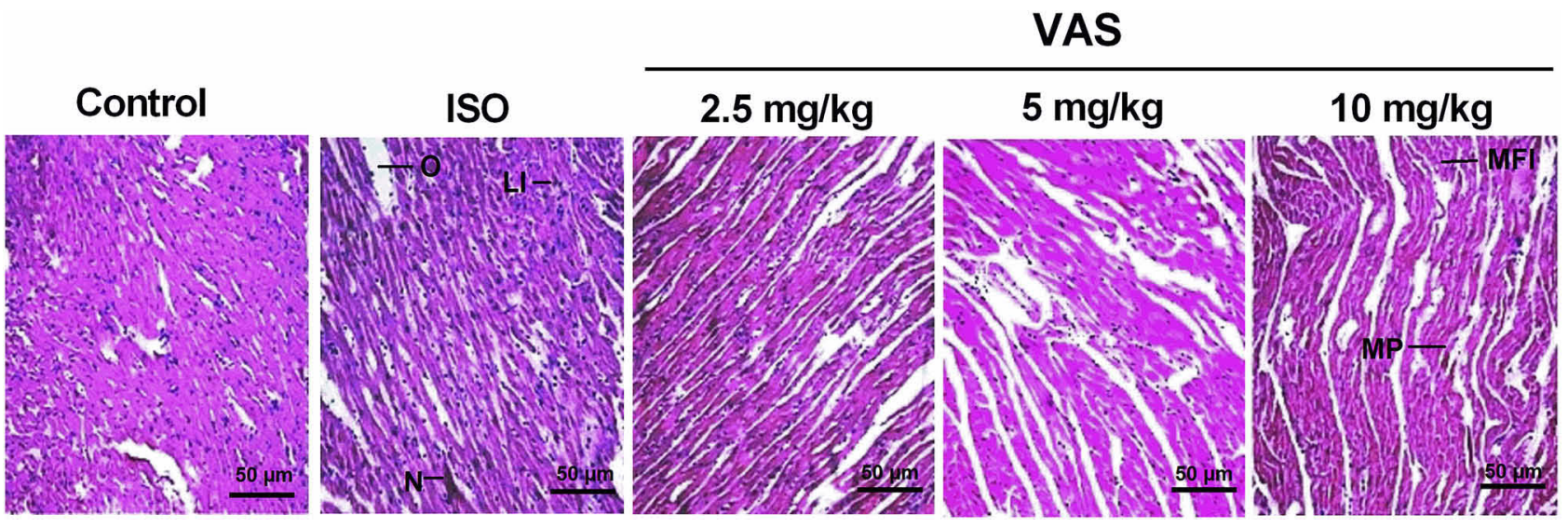

Figure 5 Effect of VAS on the architecture of myocardial tissues (mag. 40x).

Abbreviations: O, edema; LI, leucocyte infiltration; N, necrosis; MFI, mild focal inflammation; MP, myocyte proliferation.

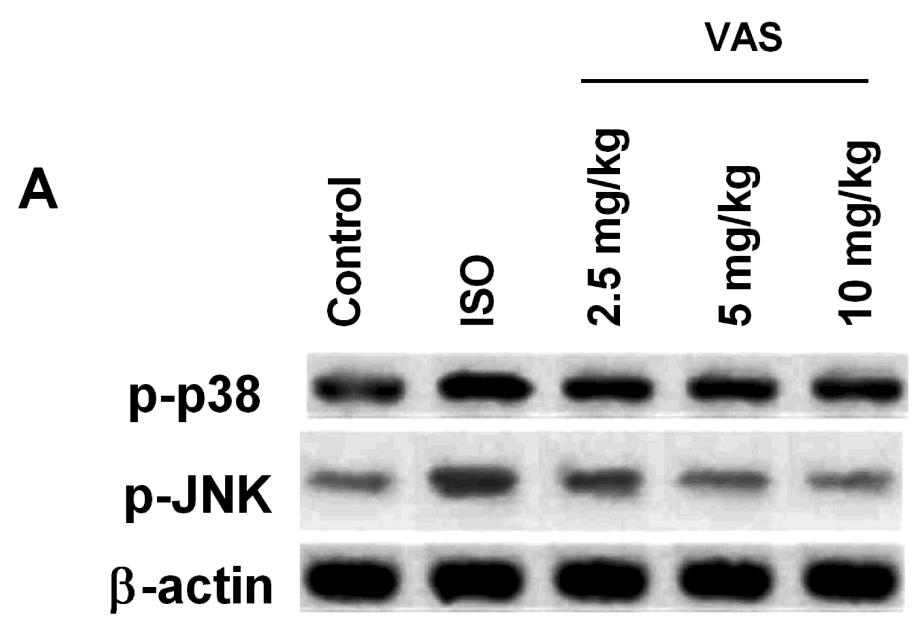

B

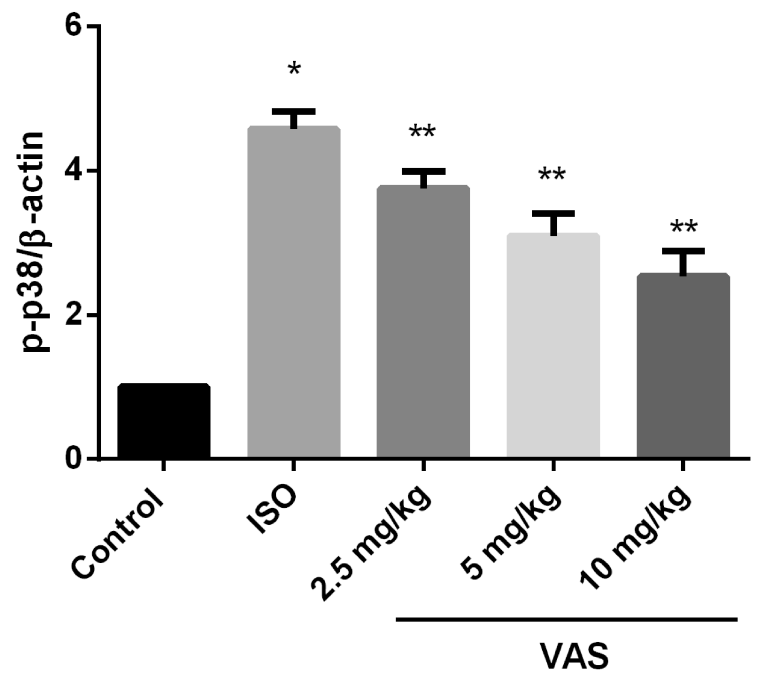

C

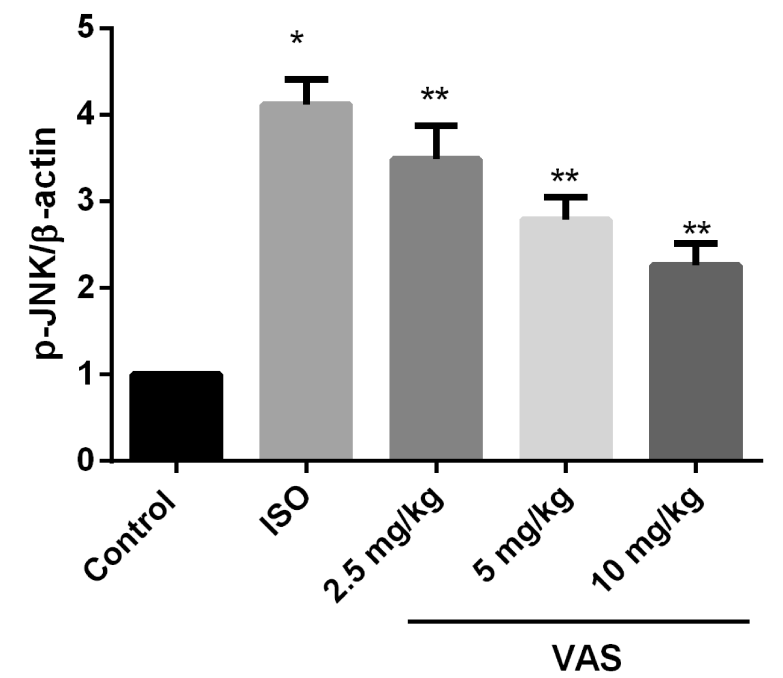

Figure 6 Western blot analysis of effect of VAS on MAPK pathway. (A) Western blot of p-p-38 and p-JNK; quantitative analysis of (B) p-p38 and (C) P-JNK. Values represent the mean \pm SEM and are representative of three independent experiments. $* P<0.05$ vs control; $* * P<0.0$ I vs ISO. 

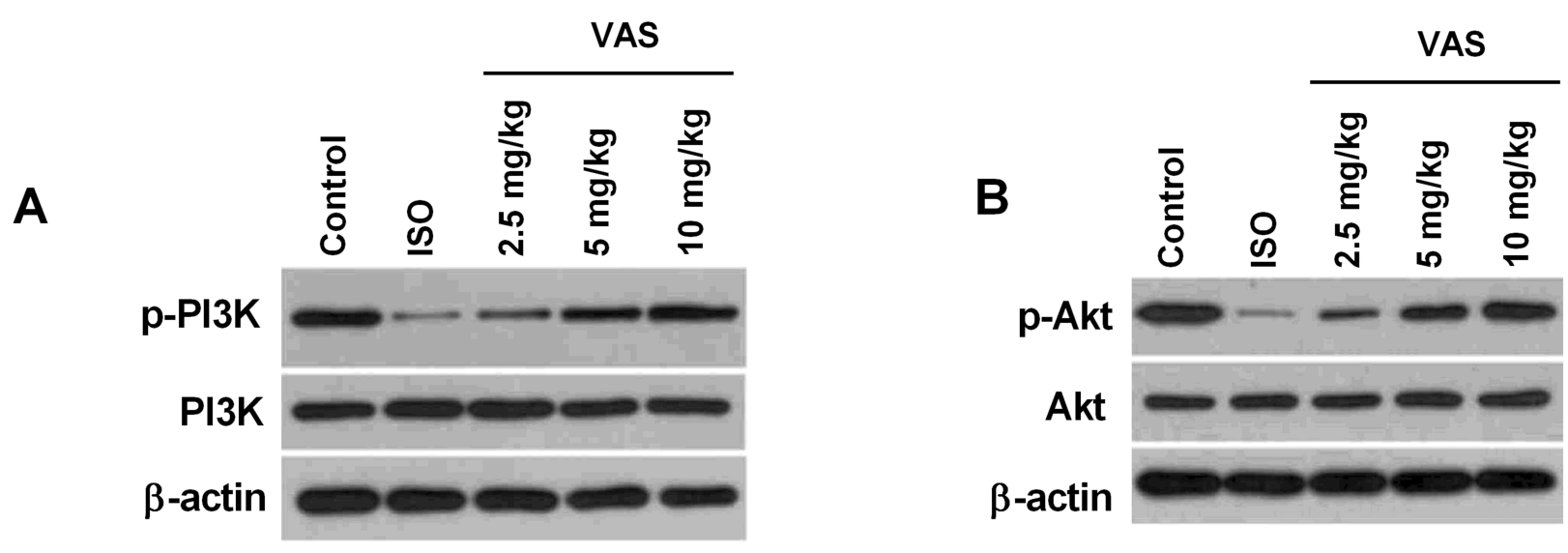

\section{C}

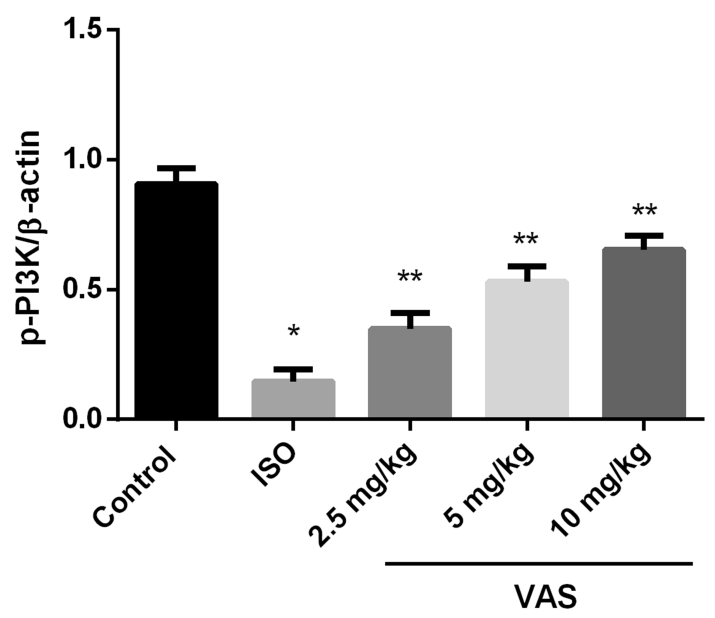

D

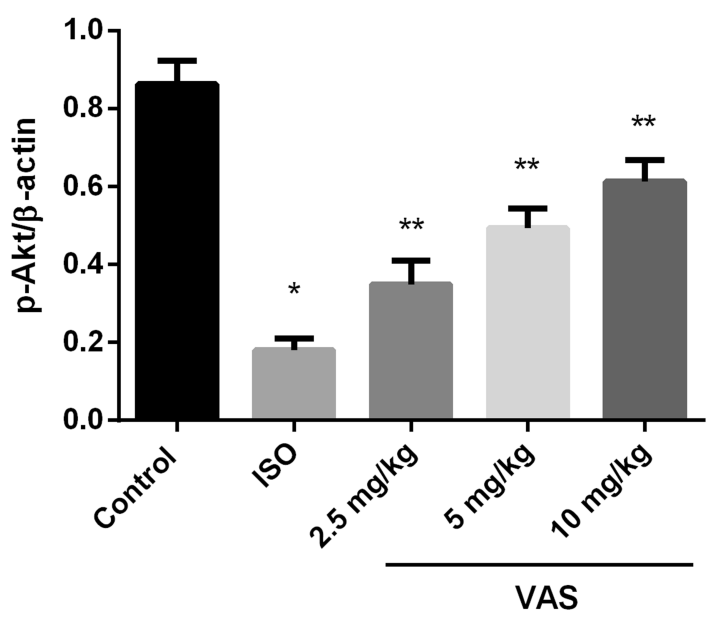

Figure 7 Effect of VAS on PI3K/Akt shown by Western blot analysis. Western blot of (A) P-PI3K and (B) p-Akt; (C and D) quantitative analysis of p-PI3K and p-Akt. Values represent the mean \pm SEM and are representative of three independent experiments. $* P<0.05$ vs control; $* * P<0.0$ I vs ISO.

\section{Discussion}

Adhatoda vasica is considered as a major source of vasicine (VAS), an quinazoline alkaloid exhibiting diverse pharmacological activity, such as, antioxidant, anti-inflammatory, anti-asthmatic, and uterine relaxant. ${ }^{32,33}$ In our study, VAS showed concentration dependent protective effect against myocardial infarction (MI) via inhibition of oxidative stress, inflammation, and PI3K/Akt signaling pathway. The least activity was reported in $2 \mathrm{mg} / \mathrm{kg}$ group, while $10 \mathrm{mg} / \mathrm{kg}$ treatment showed prominent activity.

Necrosis of myocardium is the pathological hallmark of acute MI, where creatine kinase (CK)-MB and lactate dehydrogenase $(\mathrm{LDH})$ serve as important biomarkers to ascertain its level. ${ }^{34-36}$ The results of the present study suggest that VAS causes reduction in myocardial necrosis as evidenced by reduction of elevated LDH and CK-MB.
Cardiac troponin $\mathrm{T}(\mathrm{TnT})$ is a contractile protein unique to cardiac muscle, and serves as important biomarker of myocardial dysfunction, especially in $\mathrm{MI}^{37,38}$ In our study, VAS caused reduction of TnT level which signifies its protective effect against cardiac damage. VAS also causes significant improvement of myocardial ability as suggested by enhanced left ventricular systolic pressure (LVSP) and myocardial contractility as determined in terms of $+\mathrm{dp} / \mathrm{dt}_{\max }$ and $-\mathrm{dp} / \mathrm{dt}_{\max }$. The infarct volume was also improved significantly. ${ }^{39,40}$ These results confirmed that VAS has a significant overall effect on the heart by preventing necrosis and improving myocardial function which are found to be depressed after MI. On the other hand, inflammation is another hallmark of MI as a result of the secretion of cytokines, such as TNF- $\alpha$ and IL- $6{ }^{41,42}$ The enhanced level of TNF- $\alpha$ and IL- 6 was also found to be restored to near normal in VAS treated group. 


\section{VAS}

A

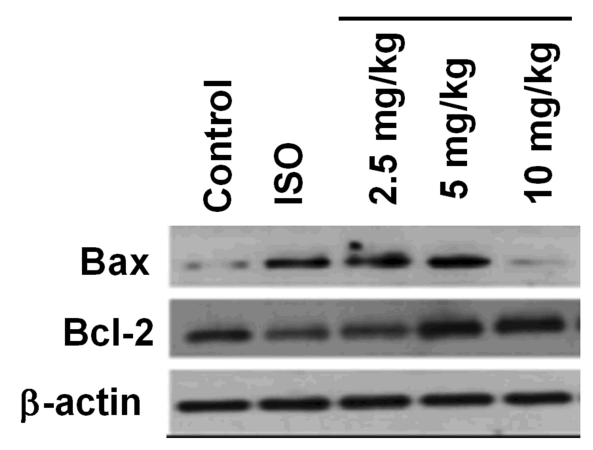

C

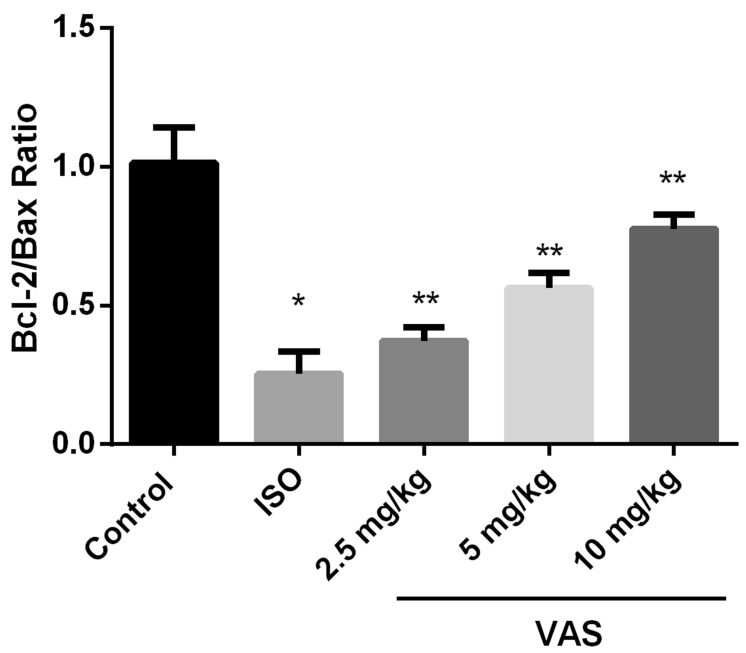

VAS

B

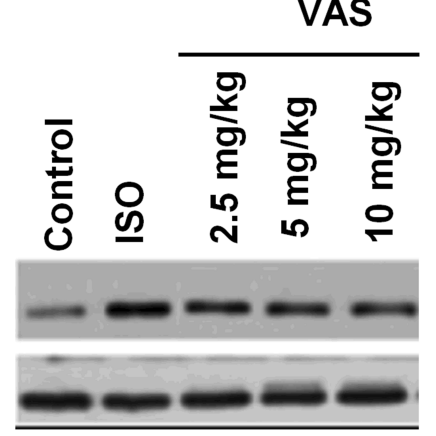

D

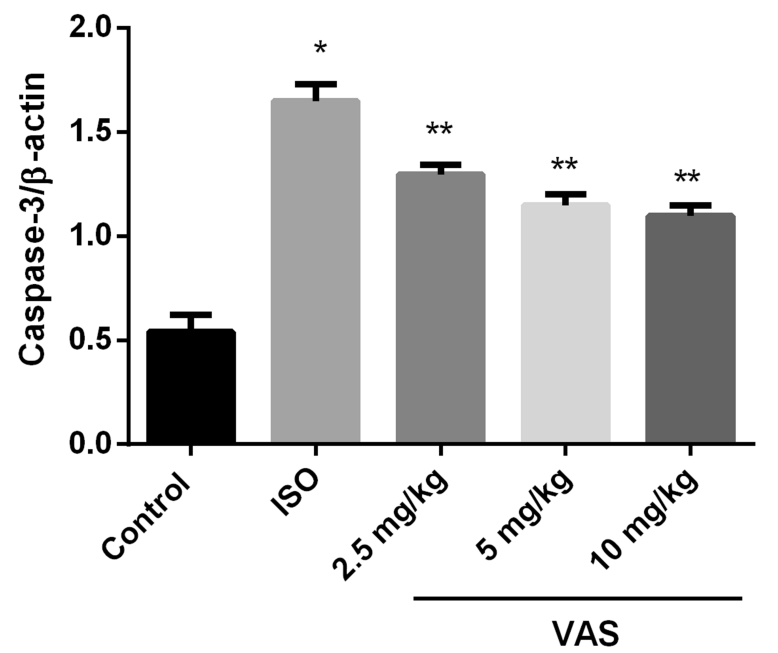

Figure 8 Effect of VAS on (A) Bax and Bcl-2, (B) caspase-3 shown by Western blot analysis. Quantitative analysis of (C) Bcl-2/Bax and (D) caspase-3. Values represent the mean \pm SEM and are representative of three independent experiments. $* \mathrm{P}<0.05$ vs control; $* * P<0.0$ I vs ISO.

These results suggest that VAS has a protective effect against MI. In the next instance, we are interested to investigate the mechanism behind this action. Oxidative stress is the major determinant of acute MI due to excessive production of ROS. It first affects infarcted myocardium, followed by the non-infarcted myocardium. ${ }^{43-45}$ Studies confirmed that treatment with antioxidant agents suppresses myocardial oxidative stress, attenuates ventricular remodeling and inflammation, and improves overall survival of animals that underwent experimentally induced MI. ${ }^{26,27,46-48}$ It has been found that VAS causes significant reduction of oxidative stress, as shown by increase in GPx and SOD level. The level of MPO and MDA was found to be significantly reduced in VAS-treated group, as compared to ISO in a dose-dependent manner. The antioxidant behavior of VAS has already been reported in lung in a rat model of toxin-induced asthma, where it causes reduction in lipid peroxidation, increases activity of the antioxidases superoxide dismutase (SOD), catalase (CAT), and glutathione $(\mathrm{GSH})$ peroxidase $(\mathrm{Gpx})$, and increases levels of GSH. $^{49,50}$ Together with these results, VAS also improved cardiac function via enhancing posterior wall thickness of the LV with concurrent increase in the mass of LV. The end-systolic volume (ESV) was also found to be elevated in VAS treated group. The histopathology of the myocardial tissues showed evidence of protective effect of VAS against MI. Intracellular mitogen-activated protein kinase (MAPK) signaling likely plays an important role in the pathogenesis of cardiac diseases, such as MI. ${ }^{51}$ Studies showed critical involvement of c-jun N-terminal kinase (JNK) and p38 MAPK cascades in the pathophysiology of cardiac hypertrophy, pathological remodeling after myocardial infarction, thus making it an attractive target for the agents providing benefit against MI. ${ }^{52-54}$ In the present study, VAS caused significant reduction in the elevated phosphorylated JNK (p-JNK) and phosphorylated 
A

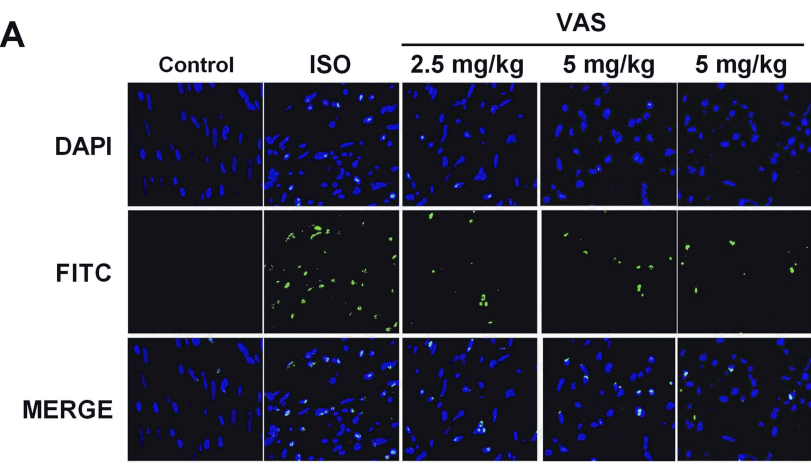

B

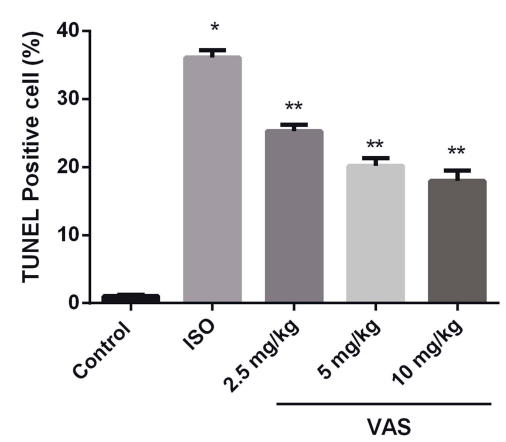

Figure 9 Effect of VAS on the myocardial apoptosis followed by ISO insult, (A) staining image and (B) representative bar-graph. Values represent the mean \pm SEM and are representative of three independent experiments. $* \mathrm{P}<0.05$ vs control; $* * P<0.01$ vs ISO.

p38 (p-p38), shown by Western blot analysis. Autophagy has been considered as a novel cell death mechanism involved in the pathophysiological process of MI, and modulation of autophagy may be considered as a promising treatment modality for MI. ${ }^{55-57}$ Thus, in the present study, VAS's effect was investigated on PI3K/Akt signaling cascade, which is known to be activated for inhibition of autophagy. In the present study, VAS caused activation of phosphorylated Akt (p-Akt) and phosphorylated PI3K (p-PI3K) in a dose-dependent manner, implicating the inhibitory effect of VAS against excessive myocardial autophagy. ${ }^{58,59}$ Recent studies indicate that, in addition to necrosis, apoptosis also plays a role in the process of tissue damage after myocardial infarction, which has pathological and therapeutic implications. Unlike necrosis, it is considered as a highly regulated and energy requiring process and characterized by shrinkage of the cell and the nucleus. ${ }^{60-62}$ Previous studies indicated that apoptosis was regulated by numerous genes including Bcl-2 and Bax. Bcl-2 is an anti-apoptotic protein which binds to the mitochondrial membrane and blocks the release of cytochrome-c to inhibit cellular death. Bax is considered as a pro-apoptotic molecule which remains in an inactive conformation in healthy cells. In response to apoptotic stimuli, Bax undergoes conformational activation and blocks the anti-apoptotic effect of Bcl-2. ${ }^{63-65}$ Caspase-3 is a class of cysteine proteases which is responsible for the proteolytic cleavage of many vital proteins related to apoptosis and plays an important role in apoptosis. ${ }^{44,66}$ In our study, we observed that VAS suppressed apoptosis in tested animals suffering from ISO-induced MI by decreasing the expression of cleaved Caspase- 3 and Bax while increasing the expression of Bcl-2. Moreover, the terminal deoxynucleotidyl transferase mediated dUTP nick end labeling method (TUNEL) was conducted to further estimate the effect of VAS on apoptosis via determining apoptotic cells. Results of TUNEL method showed that VAS causes marked reduction in apoptosis rate.

\section{Conclusion}

In summary, vasicine has a protective effect against MI in vivo. It mitigated MI insult through inhibiting oxidative stress, inflammation, and excessive autophagy to suppress apoptosis via activation of PI3K/Akt signaling pathway in a dose dependent manner, laying a foundation for the mechanism research and treatment for MI.

\section{Data Availability Statement}

The experimental data used to support the findings of this study are included within the article.

\section{Compliance With Ethical Standards}

Prior approval for all animal experiments was received from the Institutional Animal Ethics Committee of China-Japan Union Hospital of Jilin University (CJUHJU/DCL/02/2018/0045). All methods were conducted according to the Guide for Care and Use of Laboratory Animals, Institute for Laboratory Animal Research, National Institute of Health (NIH publication No. 80-23).

\section{Author Contributions}

All authors contributed to data analysis, drafting and revising the article, gave final approval of the version to be published, and agree to be accountable for all aspects of the work.

\section{Disclosure}

The authors report no conflicts of interest in this work. 


\section{References}

1. Yusuf PS, Hawken S, Ônpuu S, et al. Effect of potentially modifiable risk factors associated with myocardial infarction in 52 countries (the INTERHEART study): case-control study. Lancet. 2004;364 (9438):937-952. doi:10.1016/S0140-6736(04)17018-9

2. Roger VL. Epidemiology of myocardial infarction. Med Clin North Am. 2007;91(4):537-552. doi:10.1016/j.mcna.2007.03.007

3. Strange J, Knight C. Management of acute myocardial infarction. Medicine (Baltimore). 2006;34(5):188-194. doi:10.1383/medc.2006. 34.5.188

4. Rischpler C. A cute myocardial infarction. $Q \mathrm{~J} \mathrm{Nucl} \mathrm{Med} \mathrm{Mol}$ Imaging. 2016;60(3):236-251.

5. Steg PG, James SK, Atar D, et al. ESC guidelines for the management of acute myocardial infarction in patients presenting with STsegment elevation. Eur Heart J. 2012;33(20):2569-2619. doi:10.10 93/eurheartj/ehs215

6. Ibanez B, James S, Agewall S, et al. 2017 ESC Guidelines for the management of acute myocardial infarction in patients presenting with ST-segment elevation. Eur Heart J. 2018;39(2):119-177. doi:10.1093/eurheartj/ehx393

7. Harrington RA. Myocardial ischemia and infarction. $J$ Am Coll Cardiol. 2004;44:S10-S12. doi:10.1016/j.jacc.2004.06.025

8. Fisher SA, Zhang H, Doree C, Mathur A, Martin-Rendon E. Stem cell treatment for acute myocardial infarction. Cochrane Database Syst Rev. 2015;2015(9). doi:10.1002/14651858.CD006536.pub4

9. Reddy K. Recent advances in the diagnosis and treatment of acute myocardial infarction. World J Cardiol. 2015;7(5):243. doi:10.4330/ wjc.v7.i5.243

10. Hausenloy DJ, Yellon DM. Myocardial ischemia-reperfusion injury: a neglected therapeutic target. J Clin Invest. 2013;123(1):92-100. doi:10.1172/JCI62874

11. Van Den Borne SWM, Diez J, Blankesteijn WM, Verjans J, Hofstra L, Narula J. Myocardial remodeling after infarction: the role of myofibroblasts. Nat Rev Cardiol. 2010;7(1):30-37. doi:10.1038/ nrcardio.2009.199

12. Hofmann R, James SK, Jernberg T, et al. Oxygen therapy in suspected acute myocardial infarction. $N$ Engl J Med. 2017;377 (13):1240-1249. doi:10.1056/NEJMoa1706222

13. Ceballos RLA. Use of herbal medicines and implications for conventional drug therapy medical sciences. Altern Integr Med. 2013;02:06. doi: $10.4172 / 2327-5162.1000130$

14. Chaudhury R, Rafei U. Traditional Medicine in Asia. South-East Asia, New Delhi: SEARO; 2001:23. Available from: http://searo. who.int/entity/medicines/documents/traditional_medicines_in_asia. pdf. Accessed October 3, 2019.

15. Sumanth M. Screening of beetroot juice for anticancer acivity. World J Pharm Res. 2016;5(6):861-870. doi:10.20959/wjpr20168-6435

16. Robinson MM, Zhang X. The World Medicines Situation 2011 Traditional Medicines : Global Situation, Issues and Challenges. World Health Organization; 2011:1-14.

17. Nepali K, Sharma S, Ojha R, Dhar KL. Vasicine and structurally related quinazolines. Med Chem Res. 2013;22(1):1-15. doi:10.1007/ s00044-012-0002-5

18. Ali SK, Hamed AR, Soltan MM, El-Halawany AM, Hegazy UM, Hussein AA. Kinetics and molecular docking of vasicine from Adhatoda vasica: an acetylcholinesterase inhibitor for Alzheimer's disease. South African J Bot. 2016;104:118-124. doi:10.1016/j. sajb.2015.09.021

19. Zhao T, Ding KM, Zhang L, Cheng XM, Wang CH, Wang ZT. Acetylcholinesterase and butyrylcholinesterase inhibitory activities of $\beta$-carboline and quinoline alkaloids derivatives from the plants of genus peganum. J Chem. 2013. doi:10.1155/2013/717232

20. Singh B, Sharma RA. Anti-inflammatory and antimicrobial properties of pyrroloquinazoline alkaloids from Adhatoda vasica Nees. Phytomedicine. 2013;20(5):441-445. doi:10.1016/j.phymed.2012.12.015
21. Shahwar D, Raza MA, Tariq S, Riasat M, Ajaib M. Enzyme inhibition, antioxidant and antibacterial potential of vasicine isolated from Adhatoda vasica Nees. Pak J Pharm Sci. 2012;25(3):651-656.

22. Liu W, Cheng X, Wang Z, Wang C. The research progress of vasicine resources, pharmacological activities, pharmacokinetics, toxicity and analysis methods. Guoji Yaoxue Yanjiu Zazhi. 2013;40(4):386-395.

23. Gupta OP, Anand KK, Ray Ghatak BJ, Atal CK. Vasicine, alkaloid of Adhatoda vasica, a promising uterotonic abortifacient. Indian J Exp Biol. 1978;16(10):1075-1077.

24. Chandokhe N, Gupta OP, Atal CK. Abortifacient activity of the alkaloid vasicine through the release of prostaglandins. J Steroid Biochem. 1978;9(9):885. doi:10.1016/0022-4731(78)91053-1

25. Hertog MGL, Feskens EJM, Kromhout D, et al. Dietary antioxidant flavonoids and risk of coronary heart disease: the Zutphen Elderly Study. Lancet. 1993;342(8878):1007-1011. doi:10.1016/0140-6736 (93) $92876-\mathrm{U}$

26. Ye Y, Li J, Yuan Z. Effect of antioxidant vitamin supplementation on cardiovascular outcomes: a meta-analysis of randomized controlled trials. PLoS One. 2013;8:2. doi:10.1371/journal.pone.0056803

27. Asplund K. Antioxidant vitamins in the prevention of cardiovascular disease: a systematic review. J Intern Med. 2002;251(5):372-392. doi:10.1046/j.1365-2796.2002.00973.x

28. Dong LY, Yao LP, Zhao J, Jin KK, Qiu XX. Captopril inhibits calpain-mediated apoptosis of myocardial cells in diabetic rats and improves cardiac function. Mol Med Rep. 2018;18(2):2300-2306. doi: $10.3892 / \mathrm{mmr} .2018 .9192$

29. Chen H, Xu Y, Wang J, Zhao W, Ruan H. Baicalin ameliorates isoproterenol-induced acute myocardial infarction through iNOS, inflammation and oxidative stress in rat. Int $J$ Clin Exp Pathol. 2015;8(9):10139-10147.

30. Ma C, Jiang Y, Zhang X, Chen X, Liu Z, Tian X. Isoquercetin ameliorates myocardial infarction throughanti-inflammation and anti-Apoptosis factor and regulating TLR4-NF-B signal pathway. Mol Med Rep. 2018;17(5):6675-6680. doi:10.3892/mmr.2018. 8709

31. Liu J, Wang H, Wang Y, et al. The stem cell adjuvant with Exendin-4 repairs the heart after myocardial infarction via STAT3 activation. $J$ Cell Mol Med. 2014;18(7):1381-1391. doi:10.1111/jcmm.12272

32. Claeson UP, Malmfors T, Wikman G, Bruhn JG. Adhatoda vasica: a critical review of ethnopharmacological and toxicological data. $J$ Ethnopharmacol. 2000;72(1-2):1-20. doi:10.1016/S0378-8741(00) 00225-7

33. Gangwar AK, Ghosh AK. Medicinal uses and pharmacological activity of Adhatoda vasica. Int J Herb Med. 2014;2(1):88-91.

34. Anand Kumar G. Biomarkers in acute myocardial infarction. Natl J Basic Med Sci. 2018;8(3):137-141. doi:10.31975/njbms.2018.8 303

35. Tanwar V, Sachdeva J, Kishore K, et al. Dose-dependent actions of curcumin in experimentally induced myocardial necrosis: a biochemical, histopathological, and electron microscopic evidence. Cell Biochem Funct. 2010;28(1):74-82. doi:10.1002/cbf.1623

36. Kehl DW, Iqbal N, Fard A, Kipper BA, De La Parra Landa A, Maisel AS. Biomarkers in acute myocardial injury. Transl Res. 2012;159 (4):252-264. doi:10.1016/j.trsl.2011.11.002

37. Omland T, Pfeffer MA, Solomon SD, et al. Prognostic value of cardiac troponin i measured with a highly sensitive assay in patients with stable coronary artery disease. J Am Coll Cardiol. 2013;61 (12):1240-1249. doi:10.1016/j.jacc.2012.12.026

38. James SK, Armstrong P, Barnathan E, et al. Troponin and C-reactive protein have different relations to subsequent mortality and myocardial infarction after acute coronary syndrome: A. GUSTO-IV Substudy. J Am Coll Cardiol. 2003;41(6):916-924. doi:10.1016/ S0735-1097(02)02969-8

39. Timmers L, Lim SK, Arslan F, et al. Reduction of myocardial infarct size by human mesenchymal stem cell conditioned medium. Stem Cell Res. 2008;1(2):129-137. doi:10.1016/j.scr.2008.02.002 
40. Nahrendorf M, Pittet MJ, Swirski FK. Monocytes: protagonists of infarct inflammation and repair after myocardial infarction. Circulation. 2010;121(22):2437-2445. doi:10.1161/CIRCULATIONAHA.109.916 346

41. Kosmala W, Przewlocka-Kosmala M, Mazurek W. Proinflammatory cytokines and myocardial viability in patients after acute myocardial infarction. Int $J$ Cardiol. 2005;101:449-456. doi:10.1016/j. ijcard.2004.03.067

42. Frangogiannis NG, Smith CW, Entman ML. The inflammatory response in myocardial infarction. Cardiovasc Res. 2002;53(1):3147. doi:10.1016/S0008-6363(01)00434-5

43. Hori M, Nishida K. Oxidative stress and left ventricular remodelling after myocardial infarction. Cardiovasc Res. 2009;81(3):457-464. doi:10.1093/cvr/cvn335

44. Hashmi S, Al-Salam S. Acute myocardial infarction and myocardial ischemia-reperfusion injury: a comparison. Int J Clin Exp Pathol. 2015;8(8):8786-8796.

45. Lefer DJ, Granger DN. Oxidative stress and cardiac disease. Am J Med. 2000;109(4):315-323. doi:10.1016/S0002-9343(00)00467-8

46. Patel V, Upaganlawar A, Zalawadia R, Balaraman R. Cardioprotective effect of melatonin against isoproterenol induced myocardial infarction in rats: a biochemical, electrocardiographic and histoarchitectural evaluation. Eur J Pharmacol. 2010;644(13):160-168. doi:10.1016/j.ejphar.2010.06.065

47. Surekha RH, Srikanth BBM V, Jharna P, Ramachandra RV, Dayasagar RV, Jyothy A. Oxidative stress and total antioxidant status in myocardial infarction. Singapore Med J. 2007;48(2):137-142.

48. Rodrigo R, Libuy M, Feliú F, Hasson D. Molecular basis of cardioprotective effect of antioxidant vitamins in myocardial infarction. Biomed Res Int. 2013;2013:1-15. doi:10.1155/2013/437613

49. Roja G, Vikrant BH, Sandur SK, Sharma A, Pushpa KK. Accumulation of vasicine and vasicinone in tissue cultures of Adhatoda vasica and evaluation of the free radical-scavenging activities of the various crude extracts. Food Chem. 2011;126(3):10331038. doi:10.1016/j.foodchem.2010.11.115

50. Liu W, Wang Y, He DD, et al. Antitussive, expectorant, and bronchodilating effects of quinazoline alkaloids $( \pm)$-vasicine, deoxyvasicine, and $( \pm$ )-vasicinone from aerial parts of Peganum harmala L. Phytomedicine. 2015;22(12):1088-1095. doi:10.1016/j.phymed.2015. 08.005

51. Muslin AJ. MAPK signalling in cardiovascular health and disease: molecular mechanisms and therapeutic targets. Clin Sci. 2008;115(78):203-218. doi:10.1042/CS20070430

52. Tanno M, Bassi R, Gorog DA, et al. Diverse mechanisms of myocardial p38 mitogen-activated protein kinase activation: evidence for MKK-independent activation by a TAB1-associated mechanism contributing to injury during myocardial ischemia. Circ Res. 2003;93 (3):254-261. doi:10.1161/01.RES.0000083490.43943.85
53. Clark JE, Sarafraz N, Marber MS. Potential of p38-MAPK inhibitors in the treatment of ischaemic heart disease. Pharmacol Ther. 2007;116(2):192-206. doi:10.1016/j.pharmthera.2007.06.013

54. Ren J, Zhang S, Kovacs A, Wang Y, Muslin AJ. Role of p38 $\alpha$ MAPK in cardiac apoptosis and remodeling after myocardial infarction. $J$ Mol Cell Cardiol. 2005;38(4):617-623. doi:10.1016/j.yjmcc.2005. 01.012

55. Thygesen K, Alpert JS, Jaffe AS, Simoons ML, Chaitman BR, White HD. Third universal definition of myocardial infarction. Glob Heart. 2012;7(4):275-295. doi:10.1016/j.gheart.2012.08.001

56. Konstantinidis K, Whelan RS, Kitsis RN. Mechanisms of cell death in heart disease. Arterioscler Thromb Vasc Biol. 2012;32(7):15521562. doi:10.1161/ATVBAHA.111.224915

57. Whelan RS, Kaplinskiy V, Kitsis RN. Cell death in the pathogenesis of heart disease: mechanisms and significance. Annu Rev Physiol. 2010;72(1):19-44. doi:10.1146/annurev.physiol.010908.163111

58. Kis A, Yellon DM, Baxter GF. Second window of protection following myocardial preconditioning: an essential role for PI3 kinase and p70S6 kinase. J Mol Cell Cardiol. 2003;35(9):1063-1071. doi:10.1016/S0022-2828(03)00208-6

59. Gallo S, Sala V, Gatti S, Crepaldi T. Cellular and molecular mechanisms of HGF/Met in the cardiovascular system. Clin Sci. 2015;129 (12):1173-1193. doi:10.1042/CS20150502

60. Krijnen PAJ, Nijmeijer R, Meijer CJLM, Visser CA, Hack CE, Niessen HWM. Apoptosis in myocardial ischaemia and infarction. $J$ Clin Pathol. 2002;55(11):801-811. doi:10.1136/jcp.55.11.801

61. Frangogiannis NG. Pathophysiology of myocardial infarction. Compr Physiol. 2015;5(4):1841-1875. doi:10.1002/cphy.c150006

62. Saraste A, Pulkki K, Kallajoki M, Henriksen K, Parvinen M, VoipioPulkki LM. Apoptosis in human acute myocardial infarction. Circulation. 1997;95(2):320-323. doi:10.1161/01.CIR.95.2.320

63. Li W, Ma N, Ong -L-L, et al. Bcl-2 engineered MSCs inhibited apoptosis and improved heart function. Stem Cells. 2007;25 (8):2118-2127. doi:10.1634/stemcells.2006-0771

64. Brady NR, Hamacher-Brady A, Gottlieb RA. Proapoptotic BCL-2 family members and mitochondrial dysfunction during ischemia/ reperfusion injury, a study employing cardiac HL-1 cells and GFP biosensors. Biochim Biophys Acta Bioenerg. 2006;1757(5-6):667678. doi:10.1016/j.bbabio.2006.04.011

65. Cassidy-Stone A, Chipuk JE, Ingerman E, et al. Chemical inhibition of the mitochondrial division dynamin reveals its role in Bax/Bakdependent mitochondrial outer membrane permeabilization. Dev Cell. 2008;14(2):193-204. doi:10.1016/j.devcel.2007.11.019

66. Toldo S, Abbate A. The NLRP3 inflammasome in acute myocardial infarction. Nat Rev Cardiol. 2018;15(4):203-214. doi:10.1038/ nrcardio.2017.161

\section{Publish your work in this journal}

Drug Design, Development and Therapy is an international, peerreviewed open-access journal that spans the spectrum of drug design and development through to clinical applications. Clinical outcomes, patient safety, and programs for the development and effective, safe, and sustained use of medicines are a feature of the journal, which has also been accepted for indexing on PubMed Central. The manuscript management system is completely online and includes a very quick and fair peer-review system, which is all easy to use. Visit http://www. dovepress.com/testimonials.php to read real quotes from published authors. 